\title{
JOAQUÍN DE LACROIX Y VIDAL: \\ UN INGENIERO DE MARINA LIGADO A LA REAL SOCIEDAD ECONÓMICA DE AMIGOS DEL PAÍS DE VALENCIA.
}

\author{
José MALLOL FERRÁNDIZ* \\ Universidad de Alicante
}

El presente trabajo tiene por objeto poner de manifiesto la actuación de un destacado miembro de la Sociedad de Amigos del País de Valencia entre los últimos años del "siglo XVIII y el primer tercio del siglo XIX: Joaquín Maximiliano de Lacroix y Vidal (1759-1836). Por la envergadura de algunos de los cargos que ocupó durante su vida, debería haber sido merecedor de más páginas en la historia de las que en realidad se le han dedicado (1). Nuestra intención, sin embargo, no es la de una biografía extensa, sino la de poner en relación su doble condición de destacado ingeniero de Marina e insigne socio de la Económica Valenciana que, apoyado en sus conocimientos científicos y técnicos, trató de llevar con sus proyectos la luz a la sociedad valenciana en las postrimerías del Antiguo Régimen.

Un apellido vinculado a las armas y a la técnica.

A lo largo de todo el siglo XVIII, en cualquiera de sus escrituras posibles (de la Croix, Croix, Lacroix, La Croix, de Lacroix), el entronque del apellido Lacroix con la carrera de las armas es patente. Y no lo será menos en relación con el mundo de la técnica. Poco conocemos sobre los antepasados de Joaquín de Lacroix. Su padre, el barón de la Bruère, llegó a teniente coronel del cuerpo de Ingenieros (2) y en sus diferentes destinos fue un destacado impulsor de la primera prensa periódica española, promo- 
viendo, entre otros, el Diario de Valencia (1790), el Diario histórico y político de Sevilla (1792) y el Correo de Cádiz en 1795 (3).

Resulta, sin embargo, más dificil de establecer su vinculación con los otros Lacroix conocidos. El primero del que tenemos noticias es un tal G. La Croix, de origen francés, el cual aparece en la promoción de 1718 de los ingenieros que acompañaron a Felipe V (4). Con posterioridad, hacia la década de 1750, el teniente general Maximiliano La Croix desempeñó una destacada labor en la reforma del ejército, tarea compartida con el conde de Aranda y el conde de Gazola (5): El mismo Maximiliano fue nombrado, en 1763, Comandante General del Cuerpo de Ingenieros e Inspector General de las plazas y demás fortificaciones del reino; de esta manera, se separaban definitivamente los cuerpos de Artillería e Ingenieros (6), en cuya pugna hay que situar una de las causas del fracaso de la Sociedad Militar de Matemáticas, asentado sobre todo en la diferente concepción de los planes de estudio de Aranda, por un lado, y de M. La Croix, por otro (7).

En estos años centrales del siglo, trabajaba en el Ferrol el ingeniero José de La Croix, autor en 1752 del plano de un edificio para la fábrica de Sada (8) y que en otro lugar aparece como el ingeniero en segundo José Petit de la Croix, cuyo sueldo era de 130 escudos mensuales (9). Otro plano de un "Cañón presentado sabre dos bancos mozos con sus cuñitas" venía firmado en 1758 por Maximino de la Croix (10).

Otros dos militares que ostentaron el apellido Croix tuvieron una fuerte relación con el Reino de Valencia, puesto que ambos fueron capitanes generales del mismo. Pedro Félix Croix de Chavières, conde de Sayve, lo fue entre 1766 y 1775 (11). Por su parte, Carlos Francisco de Croix, marqués de Croix, ocupó la Capitanía en los años que iban de 1777 a 1786, precisamente los años fundacionales de la Real Sociedad Económica de Amigos del País. Venía precedido de una amplia experiencia, pues había sido Capitán General de Andalucía y de Galicia, además de Virrey de México(12). Su mandato se vió envuelto en polémica al intervenir a favor del corregidor de Alcoy, Antonio de Anguionaz y Velasco, en un tema de presunta corrupción en la fabricación de uniformes para el ejército en la Real Fábrica de Paños de Alcoy. El capitán general, pese a que después se demostró la mala fe de Anguionaz, llegó a proponerlo para un cargo de oidor en la Audiencia, acusando a los regidores Puigmoltó, Descals y otros miembros tradicionales de la oligarquía urbana de Alcoy-, de haber urdido un complot contra el corregidor (13).

Finalmente, en el Archivo General Militar de Segovia se encuentran algunos de los expedientes pertenecientes a los sujetos de los cuales hemos venido hablando, fechados entre 1769 y 1826 y que nos dan muestra de la relación del apellido Lacroix con la Armada, la Infantería y la Caballería (14). Nuestro Lacroix perteneció, como tendremos ocasión de comprobar, al primero de estos cuerpos.

Si la vinculación con la carrera de las armas es clara, no es menos con el mundo de la ciencia y de la técnica. Joaquín de Lacroix, además, de marino, fue un destacado ingeniero hidráulico. En este contexto, las ciencias útiles fueron en los inicios de las Sociedades Económicas motivo de su atención. Con poco más de un año de existencia, la 
de Valencia ya intentó "establecer una escuela de Náutica donde aprendieren el Pilotage (sic) a la manera de la últimamente puesta en Barcelona" (15). Un año después, en 1779, la Sociedad Económica Mallorquina fundó una Escuela de Matemáticas, germen de lo que sería la Escuela de Náutica, inagurada oficialmente en 1800 (16).

Con todo, nos interesa resaltar aquí la labor de Lacroix como ingeniero de marina, para lo cual se hacen necesarias unas breves líneas sobre el Cuerpo al que perteneció. Ya se ha hablado de la separación de los cuerpos de Artillería e Ingenieros en 1763. No obstante, no fue hasta 1770 cuando una Real Orden de Carlos III creaba el Cuerpo de Ingenieros de Marina, consolidado por las Ordenanzas de 1772, que habían sido inspiradas por el primer Ingeniero General, Francisco Gautier (17). La incorporación al nuevo cuerpo daba preferencia a los marinos y militares, con un plan de estudios basado fundamentalmente en las matemáticas, el dibujo y la hidráulica. Cometidos suyos serían, en definitiva, la construcción y cuidado de los buques, a los que se añadirían otras tareas relacionadas con la navegación fluvial, las fábricas de Marina (desde los telares a los altos hornos), el acopio de cáñamo para los velámenes y de madera, materia prima esencial de las naves (18).

Como correspondía, pues, a las tareas de un ingeniero de marina, en 1793, Joaquín Lacroix se hallaba en los montes de Cuenca señalando talas de madera para la Armada. Fue entonces cuando se inició su relación con la Sociedad Económica de Amigos del País de Valencia.

\section{Lacroix: un "Amigo del País".}

Pretender relatar en breves páginas la trayectoria vital de una persona es tarea difícil. Mucho más si el sujeto en cuestión desplegó toda una serie de actividades en los más diversos campos. $Y$ este es el caso de Lacroix. Su doble vertiente de ingeniero y socio-amigo del país se entrecruzó permanentemente. No obstante, sin perder de vista su condición militar, nos interesa resaltar sus aportaciones a la Sociedad Económica de Valencia. Pero aún profundizaremos más. Dado que nuestra investigación a largo plazo se centra en el estudio de las tareas científico-técnicas de la Económica Valenciana, nos detendremos sobre todo en aquellas realizaciones de Lacroix que revistieron el carácter científico-técnico propuesto. Además, su papel en la estructura interna de la Sociedad y su proyección hacia otras Sociedades, en general, y hacia la Valenciana, en particular, también serán objeto de nuestra atención.

El 10 de julio de 1793, haciéndose eco de un proyecto de Tomás Barrachina para la conducción de géneros -esencialmente trigo- desde Teruel a Valencia a través del río Turia, Joaquín de Lacroix, teniente de navío e ingeniero hidráulico, solicitaba a los Amigos del País su ingreso er. la Sociedad. Inmediatamente fue admitido en la clase de socio numerario (19). A partir de esos instantes, como socio de pleno derecho, inició sus actividades en la Económica de Valencia (20), emitiendo multitud de informes en los muchos años de permanencia en la Sociedad, en los que se constataba un predominio de los de carácter técnico. 
Era precisamente en esos informes donde Lacroix vertía sus opiniones, fundadas en unos conocimientos sólidos y sobre todo llevados a la práctica por el desempeño de su empleo militar. La Sociedad Económica supo ver en J. Lacroix un elemento valioso y le confió los más variados asuntos, hasta el punto de que en la etapa que transcurrió entre 1794 y 1802 fue uno de los cinco sujetos de más activa participación en las Juntas de la Sociedad, junto al secretario Francisco Peyrolón, Manuel de Velasco, el marqués de Valera y Tomás Domingo de Otero (21).

Tanto los Libros de Actas como el Archivo de la Sociedad, nos proporcionan multitud de testimonios de la confianza que ésta depositó en Lacroix, y de las tareas que aquél por propia iniciativa desarrolló. Ejemplos de uno y otro caso no nos faltan: propuesta de J. Lacroix sobre el modo de emitir votaciones secretas en las Juntas de la Sociedad; atracción de nuevos socios a través de sus proposiciones; comisiones de la Económica a través de las cuales se derivarían informes sobre fábricas (de lacre, de manufacturas metálicas, de carmín, de loza), máquinas (de triturar trapo, para sofocar incendios, relojes, limas, de extracción de agua de los pozos), memorias (sobre la libertad de pesca, desecación de lagunas, hornillos), cuestiones agrarias (aclimatación del pino de Riga para salvar los inconvenientes de la deforestación, sobre el maní o cachuete y el uso de su aceite, reportajes sobre el estado de la agricultura), comisiones de orden interno en la Sociedad (examen de memorias aspirantes a premio, suscripciones -al Periódico de Agricultura-, acuñación de medallas, cargos en la Diputación de la Sociedad en Madrid), o de orden educativo-benéfico (socorro a mendigos y trabajadores parados a través de "sopas económicas" o de la organización de bailes de máscaras, estudio de la posibilidad de establecer una escuela de hilar en el Grao -1798-, de implantar en Valencia el método educativo de Pestalozzi -1807- o de crear una escuela de dibujo en 1816.

Sin embargo, en este rápido repaso no se han incluido ni su proyección personal, ni sus actuaciones y proyectos más sobresalientes. Ni que decir tiene que lo primero iba estrechamente ligado a lo segundo.

De esta manera, habíamos dejado a Lacroix, a mediados de 1793, tras su ingreso en la Sociedad, estudiando el plan de hacer navegable el Turia. En su dictamen se calificaba de "muy ventajoso a ambas Provincias" -Valencia y Teruel-, pero también se señalaba el recelo de las autoridades turolenses acerca de las dificultades técnicas que entrañaría el proyecto. Lacroix proponía salir de dudas enviando a "un Ingeniero o persona inteligente en las aguas del río Guadalaviar" que estudiara la viabilidad de la idea de Barrachina. El informe concluía, ratificando esa opinión, con las siguientes palabras:

“(...) el proyecto es demasiado interesante al bien público, para abandonarle ni admitirle, sin que haya antes precedido el más maduro, y prolijo examen de sus ventajas, o perjuicios" (22).

Pero, serían otros los temas, de variada índole -agrícolas, científico-técnicos, industriales- los que ocuparían la mayor parte del tiempo dedicado por J. Lacroix, fuera de sus obligaciones militares -y a veces compartiéndolas-, a la Sociedad Económica de Amigos del País de Valencia. 
La industria del tinte había sido una de las preocupaciones iniciales de la Económica Valenciana. Su socio de mérito Luis Fernández, publicó en 1778 un Tratado instructivo y práctico del arte de la tintura, y durante esos años presentó a la Sociedad numerosos trabajos que versaban sobre esta materia. Así, en 1785, fue nombrado Director de la Fábrica de Tintes establecida en Valencia por los Cinco Gremios Mayores de Madrid(23).

Pocos años después, concretamente el 5 de diciembre de 1793, Vicente Oliag, Juan Antonio García Urreta y Joaquín Lacroix, recibían el encargo de la Sociedad de estudiar el método de blanquear lienzos propuesto por Miguel Sánchez(24). Tras un informe favorable, la comisión -a la que quedó agregado el escolapio Benito Feliu de San Pedro- se responsabilizó de velar por la seguridad del préstamo de 130 pesos hecho a Sánchez que, además, recibió una gratificación de 30 libras (25).

Con este capital quedó establecida la fábrica de blanqueo situada en la calle Quarte Extramuros, "mediante el nuevo método y uso del Gas y Lejías correspondientes" (26). Los progresos de la fábrica aconsejaron su traslado a las inmediaciones de la fuente de Encors, en el término de Ruzafa, donde recibiría libremente las aguas saponáceas de dicha fuente, ideales para blanquear en ella toda clase de piezas e hilos de lino, algodón y cáñamo (27).

La repercusión de la fábrica se extenđió más allá de Valencia, y Lacroix y el P. Benito -a petición de la Económica Aragonesa- redactaron un informe (20-VI-1797) en el que resumían el sistema empleado por $\mathrm{M}$. Sánchez; éste había adoptado el método del ácido sulfúrico del catedrático de Química de la Universidad de Madrid, Pedro Gutierrez Bueno; pero, observando algunas imperfecciones, sobre todo la pérdida de vigor del hilado y un coste excesivo, lo perfeccionó con el suficiente éxito como para lograr la protección de la Sociedad (28). El propio Miguel Sánchez había notificado públicamente su método y experiencias al analizar las materias alcalinas y ácidas utilizadas en el blanqueo (29).

Bajo estos presupuestos, y la supervisión de Lacroix, la fábrica continuaba funcionando en 1800 , empleando a once individuos y blanqueando entre diez y doce mil libras anuales de hilos y lienzos (30).

La decadencia de la fábrica no vino, como cabría esperar, de la crisis finisecular. Se trató, más bien de un problema personal. Miguel Sánchez se vió aquejado de trastornos mentales, que llevaron a Mariano Cosme -su fiador en el préstamo de los 130 pesos- a acusarle de emplear en el blanqueo "cal mezclada con meado de caballerías", procedimiento que quemaba los hilos(31). Pese a ello, Lacroix había presentado un certificado de aptitud mental de Sánchez y el compromiso de éste de devolver las 130 libras a la Sociedad, extremo que, si bien no ha sido comprobado, dudamos de su cumplimiento.

Directamente relacionado con el blanqueo de lienzos, la fabricación del ácido sulfúrico fue otra de las materias que ocupó a Lacroix. En efecto, en la Junta de 14 de septiembre de 1796, fue comisionado para averiguar qué cantidad de ácido se consumía en España, su coste y ventajas. La comisión venía causada por un memorial de 
Antonio Ballester, boticario de Catellón de la Plana, que deseaba abrir un establecimiento donde se fabricara el compuesto, solicitando la protección económica de la Sociedad (32). La petición de Ballester venía avalada por el catedrático de Química y Botánica de la Universidad de Valencia, Tomás Villanova, quien en su dictamen aseguraba que el sulfúrico de Ballester reunía las mismas propiedades que el extranjero, pudiéndose vender a un precio asequible, "pues de la combustión de una libra de azufre, se forma a lo menos una de ácido concentrado" (33).

Joaquín Lacroix, que se encontraba en Ademuz desempeñando tareas propias de su milicia cuando redactó el informe (11-X-1796), aseguraba que la ciudad de Valencia consumía entre quinientas y seiscientas arrobas anuales de ácido sulfúrico, en su mayoría procedente de Holanda e Inglaterra. Los usuarios más frecuentes eran los tintureros, blanqueadores, plateros y pintores(34).

Respecto al precio, señalaba Lacroix que, tras el encarecimiento a que dió lugar la Guerra de la Convención -se llegó a pagar a 9 rs. la libra-, éste era de 5 reales. Calculando las proporciones serivadas del experimento de Ballester, se obtenía un precio de 2 reales y 28 maravedís por libra, lo cual representaba una reducción de casi el $50 \%$ en el precio, hecho lo suficientemente significativo como para recomendar que la Sociedad otorgara su protección al proyecto del boticario castellonense, y más si se consideraba que la única fábrica existente en el país, radicada en Madrid, no podía ofrecer ese beneficio.

Prescindiendo de una terminología química en la que aún utilizaba la denominación de flogisto, en lugar de oxígeno -así llamado por Lavoisier en 1774- (35), Lacroix abogaba también por una rebaja en el precio de los elementos necesarios para la fabricación del sulfúrico: plomo, azufre y nitro. La Sociedad Económica suscribió esta opinión en una petición al rey fechada en 5 de marzo de 1797, en la que resumiendo el expediente sobre Ballester, calificaba a Lacroix como "uno de sus más hábiles individuos" (36).

Los Amigos del País ayudaron a Ballester con un préstamo de 960 reales, que éste se comprometió a devolver. La labor de Lacroix consistió en inspeccionar la fábrica. Sin embargo, Ballester se negó al examen de la misma, con lo que quedaron fraustradas las esperanzas de conseguir el ácido sulfúrico a un precio ventajoso y, de nuevo, el préstamo cayó en saco roto (37).

Un último aspecto relacionado con la química constituyó la instalación de una fábrica de albayalde en la ciudad de Valencia. Este carbonato básico de plomo era utilizado fundamentalmente por los pintores. En este caso también se trataba de conseguirlo a mejor precio que el extranjero. La Sociedad confió otra vez en los conocimientos químicos de Lacroix y le comisionó para estudiar la petición de Valero Llorens (38), avalada por los pintores Vicente Inglés, Vicente López y Francisco Royo, dado que el albayalde se ofrecía a un real más barato por libra respecto al extranjero (39).

Sorprendentemente, la petición de Llorens no era de ayuda económica, sino de asesoramiento técnico. De ahí que la Económica, a través de Lacroix, mostrara especial interés en unos momentos en los que la situación financiera de la Sociedad, así 
como la del país, era bastante precaria. Además, la única objeción alegada por Lacroix en su informe (23-IX-1801) era fácilmente salvable. De esta manera, se reflejaba:

"que aunque el método de que se sirve para la oxidación del plomo y para las preparaciones posteriores del Albayalde son los comunes que no ofrecen toda la facilidad, ni precaución de la salud de los operarios con que en el día trabajan en Inglaterra esta cal de plomo, y que de las últimas manipulaciones resulta una clase superior a las demás que con dificultad sabría obtener este fabricante, no obstante hallo disposición en él para ejecutar cuanto se le dicte para mejorar sus métodos, bajo la dirección de algún individuo socio protector que se nombre para el establecimiento y promoción de esta nueva fábrica" (40).

Atendiendo a los hechos, era obvio que el título de socio protector habría de recaer en la persona objeto de nuestro estudio (41).

V. Llorens llevó adelante su fábrica, contando con las herramientas adecuadas, aunque con algunos problemas de abastecimiento al faltarle plomo de buena calidad y a buen precio (42). En cualquier caso, con el paso de los años, la Sociedad guardó un recuerdo positivo de la labor de Lacroix como socio protector y de los progresos de Valero Llorens en la fabricación del albayalde (43), así como de las ventajas que se siguieron, sobre todo para los pintores valencianos.

Tres fueron, no obstante, las actuaciones más destacadas de nuestro socio Lacroix, en las cuales puso de manifiesto su dúplice carácter de ingeniero de marina y de "amigo del país". Nos referimos a sus trabajos sobre montes y plantíos, sobre las minas de carbón de piedra y el proyecto de construir un canal de navegación que uniera el puerto de Cullera con el Grao de Valencia. De estos tres asuntos trataremos los dos primeros, reservando el último, que por su entidad merecerá un estudio aparte en otro momento de nuestra investigación.

Por una Real Orden de 9 de enero de 1794, el Secretario de Estado de Marina, Antonio Valdés, encargaba a la Sociedad Econónica de Valencia la elaboración de un informe que expresara las especies de árboles existentes en el Reino y qué operaciones se realizaban con los mismos, amén de aquello que la Sociedad considerara de interés. La finalidad no era otra que la elaboración de una nueva Ordenanza de Montes (44).

Parecía lógico que tratándose de una orden procedente del Ministerio de Marina, y de un tema que muy bien podía competer a un ingeniero, la comisión para la elaboración del informe recayera en Lacroix, a quien se sumaron José Valcárcel, Pascual Nebot y, nuevamente, el P. Benito de S. Pedro (45).

Al igual que el resto de las Sociedades Económicas -a las que se encomendaba la misma misión en sus respectivos ámbitos de influencia-, la de Valencia envió circulares a las cabezas de los corregimientos para que se indagara sobre la calidad de los árboles. Entre los días 6 de febr rro y 15 de marzo de 1794, las autoridades de numerosos lugares del Reino enviaban su información, que reflejaba el tipo de árboles y su estado, añadiéndose algunas observaciones. Unos ejemplos nos ilustrarán más claramente desde Cinctorres, en la Gobernación de Morella (16-II-1794) se señalaba que los árboles más abundantes eran pinos negrales, encinas y robles, que crecían naturalmente con 
gran espesura, pero resultaban "inútiles para construir naves", lo cual era uno de los objetivos del ministro Valdés. Por su parte, respecto a la Gobernación de Alcoy, se indicaba (26-II-1794) que se encontraban terrenos aptos para toda clase de árboles: encinas, pinos, álamos blancos y negros, chopos, etc., tanto para monte como para las riberas de los ríos; sin embargo, la madera no era aprovechada ya que se talaba sin ningún orden al establecerse los terrenos y luego abandonarse; se añadía que la jurisdicción señorial impedía la tala de álamos, gravándola con un canon.

La evaluación de los expedientes remitidos produjo un informe de la comisión (46) en el que se afirmaba que la decadencia de los montes provenía "de la inobservancia de las providencias y órdenes Rls. expedidas sobre Montes para detener su total ruina y reponerles en su correspondte. vigor, como uno de los objetos más importantes del Estado". Además, los contínuos rompimientos de tierras y su posterior abandono no hacían más que favorecer la erosión, a lo cual contribuía también la excesiva ligereza de las autoridades a la hora de conceder licencias para talas. Se aducía, junto a todos los problemas citados, que "lo que más ha aniquilado y aniquila los Montes son las quemas, que se hacen frecuentes, y se atribuyen por lo común a los Pastores o sus coligados".

Las soluciones propuestas pasaban por una oposición a los rompimientos, a las talas indiscriminadas, a la entrada del ganado en los plantíos recientes, además de la corta de árboles viejos y de broza que impedían el crecimiento de los más jóvenes. Se añadían otro tipo de medidas como el incremento de la vigilancia o el aumento de las penas a los infractores.

Aprobada la Memoria en la Junta del 30 de abril de 1794, la Sociedad acordó su inmediata remisión a la Junta de Ministros del Consejo de Castilla y de Hacienda (47).

Pese al evidente interés del tema, éste quedó aparcado durante varios años y no volvió a aparecer en las Juntas de la Económica hasta los últimos meses de 1800 . De esta manera, al optar a uno de los premios propuestos por la Sociedad y que debían entregarse en la Junta Pública anual -que conmemoraba el cumpleaños de la Reina, el día 9 de diciembre, Joaquín de Lacroix presentó su Memoria que contiene la indicación de los Montes del Reyno de Valencia, clase, calidad, uso y abundancia de sus maderas, Ríos y carreteras que facilitan su extracción, causa de la decadencia de los Bosques, medios de evitarla y asegurar su permanencia.

La Sociedad, por acuerdo de 26 de noviembre de 1800 , premió el trabajo de Lacroix (48), cuyo lema no era de lo más optimista, al aseverar: "Temo que los que vinieren después de nosotros han de tener mucha queja de que se los dejamos consumidos, y plegue a Dios que no lo veamos en nuestros días".

A la concesión del premio, consistente en una medalla de oro acuñada con el nombre del autor, se unió el título de Socio de Mérito, que distinguía a Lacroix como uno de los miembros más acreditados de la Económica.

Un Extracto de dicha Memoria (49) fue leído en la Junta Pública de 9 de diciembre de 1800 , y la publicación de la misma apareció al año siguiente tras las correcciones pertinentes (50). 
Lo curioso de la Memoria estriba en que -además de los conocimientos derivados de su formación- Lacroix debió aprovechar con toda seguridad la información del expediente de 1794, adaptándolo e incluso copiando algunas de las sugerencias del mismo. En todo caso, la Memoria nos aporta noticias sobre el tema y sobre el propio Lacroix, quien, no pudiendo olvidar su condición de marino, reivindicaba la necesidad de mantener numerosos buques de guerra para proteger el comercio. Señalaba la abundancia de maderas en el Reino, pero se hacía eco de su decrecimiento por los "contínuos usos para Arquitectura naval, civil e Hidráulica"; así, destacaba el interés del pino camasco para la construcción de buques de comercio y embarcaciones menores de guerra.

En su página 186 advertía sobre un problema que hoy es un hecho gravemente preocupante, anticipándose al escribir:

"La aniquilación total de los bosques, y aún su disminución excesiva puede pues ocasionar grandes variaciones en los climas y estaciones relativamente a una determinada provincia".

El punto $3^{\circ}$, que trataba sobre las causas de la decadencia de los arbolados, venía a reflejar -con algún añadido importante- las consideraciones vertidas en el Informe de 1794: 1) el aumento de población y comercio; 2) el excesivo rompimiento de tierras; 3 ) los incendios de los pastores y otros maliciosos; 4)excesivos cortes y rozas hechas sin conocimiento; 5) la falta de explotación de las minas de carbón de piedra que abundan en este Reino; y 6) las mismas leyes promulgadas para favorecer el aumento y cría de arbolados.

De igual modo sucedía en el apartado $4^{\circ}$ y último, que trataba de los medios para evitar la decadencia: nombramiento de responsables vigilantes de montes y de repoblación; formación en cada pueblo del Reino de una Junta de Montes y Agricultura, bajo el cuidado de un jefe principal que visitaría la zona para corregir los abusos e introducir mejoras que no resultaran gravosas para los vecinos.

La repercusión de la Memoria fue importante. En marzo de 1802, desde Madrid, Lacroix escribía a la Sociedad pidiendo el envío de su trabajo y una representación a Godoy para contribuir a la elaboración del un "Nuevo Reglamento para la conservación y aumento del arbolado de montes" (51).

El pensamiento de la Sociedad sobre la valía de su socio y las intenciones de aplicación de su Memoria se reflejaban en el papel remitido al valido de Carlos IV, en el que se solicitaba que mandara

"examinar el sistema de D. Joaquín Lacroix y hallándolo tan útil y propio como lo ha juzgado la Sociedad tendrá V.E. a bien autorizar a este Cuerpo Patriótico para que pueda ponerlo en práctica solo por vía de encargo en uno o más pueblos o en algín terreno particular y bajo la dirección del Autor, pues prescindiendo de sus vastos conocimientos en la materia de que trata, de los qu posee en la mayor parte de las ciencias exactas y de los relevantes méritos que ha contraído en la Sociedad desde que fue recibido en ella; su comisión facultativa para la dirección de cortes de madera para la Real Armada, su mismo honor 
y la confianza que merecería a V.E., le estimularía a prestar nuevas luces, corregir y rectificar si era necesario alguna parte de sus sistema en la Práctica y vencer por medios suaves los obstáculos imprevistos que ofrecería su ejecución" (52).

La importancia del tema para el Gobierno era evidente y una ley "De los Montes y Plantíos, su conservación y aumento" ampliaba las competencias en la materia a la jurisdicción de Marina y reforzaba las ordenanzas de 1748 y 1751 (53). La medida, tras la consulta del Consejo de Guerra de 6 de agosto de 1805, fue comunicada en circular de octubre de ese año, como negro presagio de lo que sería el desastre de Trafalgar, ocurrido el día 20 de ese mismo mes.

Con toda probabilidad se tuvo en cuenta el Prospecto de una obra de Montes y Bosques (54) que Lacroix iba preparando y en el que separaba los montes según estuvieran bajo la jurisdicción del Consejo de Castilla o de Marina. Pero en aquellos momentos la situación no era la más apropiada, y los acontecimientos posteriores se encargarían de demostrarlo.

Clara correspondencia con los montes guardaba otro de los aspectos por los que el ingeniero mostró interés: la explotación de las minas de carbón de piedra. Ya lo había escrito en su anterior Memoria y el Gobierno trató de regularlo por

"las considerables ventajas que de su beneficio por la escasez de montes y aumento del consumo de leñas (...), pudiéndose contar por esta razón el carbón de piedra entre los géneros de primera necesidad" (55).

La normativa legal se componía de un conjunto de cinco disposiciones que, entre 1780 y 1793 , dieron cuerpo a una serie de reglas que articulaban la explotación de las minas (56), reservando los privilegios reales y concediendo franquicias a los que las trabajasen. Las leyes, además, hacían especial hincapié en las necesidades de la Marina pues, para el trabajo en las minas se podían señalar cortes de madera, excepto en los montes reservados a la Armada.

Obedeciendo las directrices gubernamentales, las Sociedades Económicas pusieron a sus más destacados sujetos a trabajar en el asunto. Fruto de esas tareas fueron memorias como las de Jovellanos y Pereda en el norte de España (57), o la que presentó Diego de Torres en las Juntas de la Económica Aragonesa acerca de las minas de carbón de piedra de Utrillas (58). Torres recomendaba el uso del carbón natural como lo venían haciendo las naciones desarrolladas -Alemania, Francia, Inglaterra y Suiza-, para paliar la decadencia de los bosques, y seguía la obra de Mr. Morand, Du charbon de terre e de ses Mines, en cuanto a la parte técnica, demostrando también estar al día en el conocimiento de la literatura médica sobre la insalubridad de las minas y su remedio.

Hacia esas mismas fechas, la Valenciana recibía una carta del Intendente Pedro Escolano de Arrieta, instándola a buscar medios y sitios donde se encontrara el carbón, "teniendo presente los métodos que se leen en la Enciclopedia, y otros autores extranjeros" (59). El P. Benito de San Pedro inició sus investigaciones sobre el tema centrándose en la zona castellonense de Ribesalves (60). 
La intervención de Lacroix tuvo lugar poco después de su ingreso en la Sociedad, la cual le comisionó en la Junta de 18 de febrero de 1795 para que informara sobre la petición de Onofre Vicher, un maestro de primeras letras que había descubierto una mina en el término de Chelva (61). Vicher solicitaba, argumentando la buena calidad del carbón extraído, una ayuda de la Sociedad para la explotación de la veta.

El informe de Lacroix no dió opción a tal subvención; tras un detenido análisis químico del carbón, valoraba escasamente la tarea de O. Vicher, desengañándole, pues

"al parecer cree que la explotación de una Mina de Carbón no tiene más ciencia que la de hacer excavaciones en el pasaje donde se halla este fósil; pero lo cierto es, que para no perder las venas y que produzca todas las utilidades que experimentan los extranjeros, es necesario muchos conocimientos y caudales que solo puede suplir el Soberano o las grandes compañías que se forman en otros Reinos para emprender esta clase de trabajos" (62).

Con motivo de haberse publicado en el programa de premios de la Sociedad de Valencia para 1802, uno de 300 Rs. y medalla de plata a la memoria que mejor describiera las utilidades del carbón de piedra, Lacroix presentó la que iba encabezada por el lema -que parecía calcado de la ley- siguiente: "La escasez de montes, y la decadencia de los que existen hace que el carbón fósil o de piedra pueda ya considerarse como género de primera necesidad". Su trabajo resultó premiado y, aunque Lacroix aceptó la medalla, rehusó los 300 Rs., atendiendo sin duda a la delicada situación que atravesaba la Económica (63).

La Memoria (64), que constaba de doce capítulos, comenzaba quejándose de lo poco escrito en castellano acerca del tema. Dado el frecuente intercambio entre las Sociedades de Valencia y Zaragoza, parece probable que conociera la Memoria de Diego de Torres -ésta se halla en la Biblioteca de la Valenciana-, pero no la cita. Sin embargo, el trabajo de Lacroix sí tuvo su repercusión en la Aragonesa, al hacer referencia a la mina de Utrillas, explotada entonces por una empresa alemana (65).

A lo largo de 108 páginas, el entonces capitán de fragata, analizaba el origen del carbón en sus diferentes tipos, su relación con la química, los lugares más comunes donde se podía hallar en Europa y en el Reino de Valencia; pero tampoco dejaba de lado los problemas derivados de la extracción, tanto en lo concerniente a la localización de las minas, su ventilación, la peligrosidad de las explosiones, la eliminación del agua de los pozos, como a la actuación en caso de asfixia y la utilización del instrumental técnico necesario.

Con todos estos epígrafes, la Memoria puede considerarse bastante completa, pero fundamentalmente si se atiende a los profundos conocimientos químicos y de historia natural, sobre todo regnícolas, pues contó con fuentes de primera mano del país, según se desprende de sus contínuas citas: Bowles, con su Introducción a la historia natural y a la geografía física de España; las Observaciones ... de Cavanilles; el Tratado de arquitectura civil de Benito Bails; o la obra del Dr. en Medicina Tomás de Villanova sobre los ahogados y su recuperación.

Pero, también la bibliografía extranjera tuvo su influencia en la Memoria. Al igual 
que Diego de Torres, el trabajo más citado era el de Mr. Morand, tratándose seguramente de una edición posterior, a juzgar por su nuevo título: Art d'exploiter les Mines de Charvon de terre. Otros trabajos destacados que cita Lacroix son: "Memoire sur les Charbons de terre" (Journal Economique du mois d"Abril de 175I) de Mr. Zimmerman; la Teorie complete du tout ce qui regarde le Charvon de terre de Triewald; el Examen Chimique du Charvon de terre de Kurella; o la obra de Christian Herrgen, que cita sin reproducir su título, Descripción geognóstica de las rocas (66), aparecida ese mismo año de 1802.

Con todos estos componentes, Lacroix proponía una mayor acción por parte del Estado con el fin de lograr un mejor aprovechamiento de las minas, lo cual habría de beneficiar a la conservación de los montes, recordando en este punto su memoria premiada en 1800 .

En el trabajo manuscrito se perseguía como último objetivo la utilidad general, mostrándose la disposición de hacer las rectificaciones necesarias para que la obra viera la luz con un carácter científico. La corrección fue encomendada a dos personas. El encargado de las cuestiones científicas, Juan Sánchez Cisneros, fue autor en 1804 de la Memoria sobre los caracteres orictognósticos del carbón mineral, clasificación de los hallados en Valencia (67); precisamente, el vocablo orictognosia venía a ocupar el lugar de geología, vóz que aún no se había popularizado. Pese a pequeñas discrepancias con los cálculos de Lacroix respecto a los costes de extracción del carbón, Cisneros aprobaba la Memoria, no obstante calificar su estilo de "muy duro y difuso". A nuestro entender, la Memoria impresa pulió los defectos de estilo, pues su lectura -salvando la manera de escribir de la época- es fluida y sencilla.

Nos proponemos abordar, finalmente, el cursus honorum de nuestro personaje. En las páginas antecedentes hemos verificado la diversidad de actividades llevadas a cabo por Joaquín Lacroix en su calidad de "amigo del país". Junto a sus opiniones, de evidente peso en el seno de la Sociedad, se han vertido las de la propia Económica sobre la valía de Lacroix. En su currículum habría, pues, que separar -como proponíamos al iniciar nuestro estudio- su doble condición de militar y de miembro de la Sociedad.

Como marino, desde su alta en la Academia de Guardiamarinas del Ferrol en 1776(68), ocupó todos los empleos posibles, ascendiendo en 1825 a Jefe de Escuadra. Como Ingeniero de Marina, cuerpo en el que ingresó en 1788, a la vez que ascendía a teniente de fragata (69), desempeñó las más variadas misiones -principalmente los cortes de madera para los arsenales-, y destinos: Ingeniero en segundo en Cartagena y Valencia, Ingeniero en Jefe de la Real Armada (70), o Comandante de Ingenieros en el arsenal de La Carraca en 1809 (71).

De sus empleos militares derivaron otros de rango político que aparecen en la reseña biográfica. Pero nos interesa también su evolución en la Sociedad, en la que perma- 
neció desde su ingreso en 1793 hasta su fallecimiento en 1836. Profesó los títulos de Socio Numerario y desde 1800 el de Socio de Mérito. Precisamente en ese año y en el siguiente, como socio más antiguo de los presentes, presidió varias Juntas de la Económica (72). Durante esos años recayeron en él numerosas comisiones para examinar las memorias aspirantes a los premios de la Sociedad, encargándose además de la redacción de un Extracto de las Actas de 1802 para presentarlas a la familia real, visita en la cual Lacroix representó un sensible papel (73).

Atendiendo a su "patriotismo" y su "inteligencia y aplicación a todos los ramos de las ciencias exactas físico-matemáticas y político-económicas", la Sociedad redactó un escrito dirigido al Secretario de Estado, Pedro Ceballos, en el que

"considerando su superior mérito digno de ser premiado por la beneficencia del soberana (...) y al premiar el sobresaliente mérito de este vasallo amante del país, sirviese el ejemplar de ser atendida la recomendación de la Sociedad, de poderoso estímulo a los demás que se dedican en los Cuerpos Patrióticos a llenar de gloria a la Nación como de felicidad al Estado" (74).

Con su visita a la Corte en 1802 fue tomando contacto con miembros de otras Sociedades Económicas, especialmente la de Cantabria, promoviendo en esos momentos la creación de una Junta de Diputación de la Sociedad en Madrid, de la que fue nombrado Secretario el 17 de marzo de ese año (75). Una de las tareas que le fue encomendada en su cargo madrileño fue la búsqueda de una dotación ofcial para la Sociedad en un momento en que las cuotas de los socios no bastaban para satisfacer los proyectos de la misma (76). Tras el fallecimiento del duque de Híjar, Lacroix ocupó la Presidencia de la Junta de Diputación el 14 de enero de 1818 y sirvió el empleo -compaginándolo con sus destinos públicos- hasta 1833 , "en que su avanzada edad, achaques y privación del órgano del oído, le impidieron ocuparse de todo trabajo mental, de bufete, y asistencia a las sesiones" (77).

Otros honores que atestiguaron la reputación de Joaquín de Lacroix fueron su cargo como Ministro del Consejo de la Guerra, la Gran Cruz de San Hermenegildo y sus condecoraciones por la rendición de la escuadra francesa en Cádiz y Chiclana(78); además de la pertenencia a la Sociedad Económica de Valencia, acreditó su presencia como numerario de la Matritense y correspondiente de la Cantábrica, Aragonesa, de Vera, Granada y Murcia(79).

Retirado de la vida pública, falleció en Valencia el 25 de mayo de 1836 a la edad de 76 años "y más de 60 de honrosos servicios con la reputación de un celoso, entendido y probo funcionario" (80).

\section{CONCLUSION}

Proyectos de navegabilidad, blanqueo de lienzos, fabricación de sulfúrico y albayalde, memorias sobre montes o sobre el carbón de piedra, constituyeron un capítulo 
importante de los trabajos de Joaquín Maximiliano de Lacroix y Vidal dentro de la Sociedad Económica de Amigos del País de Valencia.

El Plan que respecto a las ciencias, tanto básicas (Física, Química, Botánica, Mineralogía, $\mathrm{H}^{\mathrm{a}}$ Natural ...) como aplicadas (Agricultura, Mecánica, Hidráulica, Aritmética, Política ...), diseñó Campomanes para su desarrollo en las Sociedades Económicas, tuvo un fiel partidario en Lacroix. Unas líneas aparecidas últimamente vienen a corroborar nuestra afirmación:

"Si no se conocía bien la acción química de los mordientes, de los blanqueadores y de los tintes, difícilmente se conseguirían buenas sedas estampadas. Si no se sabían calcular los rendimientos de las máquinas hidráulicas difícilmente se podría establecer con rigurosidad la conveniencia de su inversión. Por último, si se desconocía la minería y la metalurgia pocos yacimientos podrían encontrarse, explotarse racionalmente y beneficiarse de una manera eficaz" (81).

En este sentido, quizá más figuras como Lacroix habrían contribuido a un mejor impulso del fallido proceso de industrialización de España. Pero este planteamiento queda aún lejos de nuestro campo de conocimientos.

\section{APENDICE}

Reseña biográfica de Joaquín de Lacroix y Vidal

1759. Nace el 12 de febrero en El Ferrol.

1776. El 11 de marzo obtiene la plaza de Guardiamarina en el Departamento ferrolano.

1778. 8 de agosto, asciende a Alférez de Fragata.

1784. 24 de enero, asciende a Alférez de Navío. Ese mismo año contrae matrimonio.

1788. 2 de mayo, asciende a Teniente de Fragata e ingresa en el Cuerpo de Ingenieros de Marina.

1790. 20 de junio, asciende a Teniente de Navío.

1793. 10 de junio, ingresa en la Real Sociedad Económica de Amigos del País de Valencia como Socio Numerario.

1794. Asciende a Capitán de Fragata el 14 de marzo.

1800. El 26 de noviembre es nombrado Socio de Mérito de la Valenciana por su Memoria sobre los Montes del Reino.

1801. 25 de mayo, es admitido como Académico de Mérito en la Real Academia de San Carlos de Valencia. 
1802. 17 de marzo, es nombrado Secretario de la Junta de Diputación de la Sociedad Económica en Madrid.

1802-1803. Presta sus servicios como Ingeniero en Segundo del arsenal de Cartagena. En esas fehas debió convertirse en socio-libre de la Academia Médicopráctica de Cartagena.

1804. Vuelve a Valencia como Ingeniero en Segundo de Marina.

1806. 1 de abril, asciende a Capitán de Navío. Además, en la Lista de Socios de la Económica figura como Ingeniero en Jefe de la Real Armada.

1809. Comandante de Ingenieros en el arsenal de La Carraca.

1810-1814. Interviene en la Guerra de Independencia, prestando distinguidos servicios en el sitio de la isla gaditana por el ejército francés del Mariscal Soult.

1814. 20 de agosto, asciende a Brigadier Graduado y el 18 de diciembre es nombrado Académico Honorario de la Real de San Carlos. Ese mismo año alcanza el puesto de Fiscal Militar del Supremo Consejo del Almirantazgo, adquiriendo poco después la antigüedad de Ministro.

1815. 5 de junio, asciende a Brigadier efectivo.

1815-1819. Como Fiscal Militar interviene en el Proyecto del Puerto de Cullera y Canal de Navegación hasta Valencia. En esos años desarrolla sus actividades en Madrid.

1818. 14 de enero, sustituye en la Presidencia de la Junta de Diputación de la Sociedad en Madrid al fallecido duque de Híjar.

1819. Al suprimirse el Almirantazgo a principios de ese año, pasa su personal al Consejo Supremo de la Guerra, quedando Lacroix como Ministro cesante del mismo. Poco después, desempeñó interinamente y por algunos meses la Comandancia General de Ingenieros de Marina.

1824. 21 de marzo, se le concede plaza efectiva de Consejero en el Supremo de la Guerra.

1825. 14 de julio, asciende a Jefe de Escuadra.

1825-1828. Por esos años asciende a General. Concretamente en 1826 aparece en una relación militar como Mariscal de Campo, y en la Lista de Socios de la Económica de ese año, con el no 5, se cita: "Exmo Sr. Marques de la Crix (sic)", que no puede ser otro que el propio Lacroix.

1828. 26 de agosto, se le concede la Gran Cruz de San Hermenegildo.

1831. 31 de julio, se jubila del Consejo de la Guerra.

1833. Deja, por su avanzada edad y achaques, el cargo de Presidente de la Junta de Diputación de la Económica en Madrid.

1836. Muere en Valencia el 25 de mayo y la Sociedad Económica le dedica un Elogio el día 31 de mayo. 


\section{NOT A S}

* Este artículo se enmarca dentro de nuestra Tesis Doctoral en curso sobre los aspectos científico-técnicos de la Sociedad de Amigos del País de Valencia que ha recibido una Beca para la Formación del Personal Investigador por parte de la Consellería de Cultura, Educación y Ciencia de la Generalitat Valenciana en 1989.

(1) La bibliografia al uso sobre la Armada Española no guarda mención sobre la vida y tareas desempeñadas por Joaquín Lacroix. Tan solo en una obra -a la cual se debe gran parte de la reseña bibográfica que aparece al final de nuestro trabajo- nos proporciona alguna información. Vid. Francisco de Paula PAVIA: Galería Biográfica de los Generales de Marina, Jefes y Personajes Notables que figuraron en la misma corporación desde 1700 hasta 1868. Por el Vice-Almirante $D$. ..., vol. IV, Apéndice, Madrid, 1874, pp. 67-68.

(2) Real Sociedad Económica de Amigos del País de Valencia (en adelante, RSEAPV.). 1836, C-91, V. Varios, n² 2. "La Sociedad Económica de Valencia al Escmo (sic) Sr. D. Joaquín de La Croix y Vidal".

(3) Sobre la figura del barón de la Bruère y su vinculación con el naciente periodosmo, vid. Luis Miguel ENCISO RECIO: "La prensa y la opinión pública", Historia de España Menéndez Pidal, vol. XXXI-I, “La época de la Ilustración. El Estado y la cultura (1759-1808)”, Madrid, 1987, especialmente, pp. 63, 107, 110 y 125.

(4) Horacio CAPEL, Joan Eugeni SANCHEZ y Omar MONCADA: De Palas a Minerva. La formación científica y la estructura institucional de los ingenieros militares en el siglo XVIII. Barcelona, 1987, p. 32.

(5) A. LAFUENTE y J.L. PESET: "Las academias militares y la inversión en ciencia en la España Ilustrada (1750-1760), Dynamis, n² 2, Universidad de Granada, 1982, p. 195.

(6) Horacio CAPEL et al.: op. cit. pp. 63-64.

(7) Ibid., pp. 180-181. Esta cuestión ha sido resaltada también por A. LAFUENTE y J.L. PESET: art. cit., pp. 197-198.

(8) H. CAPEL et al.: op. cit., pp. 172-173.

(9) José Patricio MERINO NAVARRO: La Armada Española en el siglo XVIII, Madrid, 1981, p. 52.

(10) H. CAPEL et al.: op. cit., p. 153.

(11) Pedro MOLAS RIBALTA: "Militares y togados en la Valencia Borbónica", Actes du Ier. Colloque sur le Pays Valencien a l'epoque Moderne, Université de Pau, 1980, pp. 178-179 y 185.

(12) Ibid.

(13) Sobre esta polémica y sobre el asentamiento del sistema corregimental en el XVIII valenciano, vid. el reciente estudio de Enrique GIMENEZ LOPEZ: Militares en Valencia (17071808), Alicante, 1990. La polémica en pp. 156-157.

(14) Archivo General Militar de Segovia. Indice de Expedientes Militares. tomo II, Madrid, 1959, p. 452.

(15) RSEAPV. Actas I (1776-1778), fol. 231. Junta de 27 de mayo de 1778. Vid. además, 1778. C-7, V. nº 1 .

(16) Horacio CAPEL: Geografía y matemáticas en la España del siglo XVIII, Barcelona, 1982, p. 201. 
(17) J.P. MERINO NAVARRO: op. cit., pp. 20 y 56-57.

(18) Ibid., pp. 60-61.

(19) RSEAPV. Actas IV (1791-1793), fols. 152-152v.

(20) La Sociedad de Valencia ha sido exhaustivamente estudiada por Francisca ALEIXANDRE TENA: La Real Sociedad Económica de Amigos del País de Valencia. Marco jurídico, estructura social y financiación (1776-1833), Valencia, 1983. A Joaquín Lacroix dedica una pequeña reseña en la p. 225. De la misma autora: Catálogo de la Biblioteca de la Real Sociedad Económica de Amigos del País de Valencia, Valencia, 1972, y Catálogo documental del Archivo de la Real Sociedad Económica de Amigos del País de Valencia, Valencia, 1978.

(21) Manuel LOPEZ TORRIJO: Educación y Sociedad en la Valencia llustrada. Labor educativa de la Real Sociedad Económica de Amigos del País de Valencia, Valencia, 1986, p. 128.

(22) RSEAPV. Actas IV (1791-1793), fols. 165-167. Junta de 9 de octubre de 1793.

(23) Pedro MOLAS RIBALTA: "La Junta de Comercio", en M. SELLES, J.L. PESET y A. LAFUENTE (comp.): Carlos III y la ciencia de la llustración, Madrid, 1988, pp. 212-213. Sobre las actividades de Luis Fernández en las Juntas de la Económica, vid. RSEAPV. Actas I (1776-1778), passim.

(24) RSEAPV. Libro Copiador de Oficios y Avisos... (1793-1803), pp. 6-7.

(25)Ibid. p. 9.

(26) Diario de Valencia, martes 22 de julio de 1794.

(27) RSEAPV. 1796. C-26, II. Industria, comercio y artes, $n^{2} 2$. Informe de Joaquín Lacroix y Benito de San Pedro de 6 de abril de 1796.

(28) RSEAPV. 1797. C-27, V. Correspondencia de Sociedades, $\mathrm{n}^{2} 2$.

(29) Diario de Valencia, sábado 8 de abril de 1797.

(30) RSEAPV. Actas V (1793-1803), p. 473. Junta de 10 de septiembre de 1800.

(31) Ibid. p. 729 . Junta de 6 de octubre de 1802.

(32) Ibid. pp. 212-213.

(33) RSEAPV. 1796. C-26, II. Industria, comercio y artes, n³.

(34) Ibid.

(35) Juan VERNET GINES: Historia de la Ciencia Española, Madrid, 1975, pp. 186-187.

(36) RSEAPV. Libro Copiador de Oficios y Avisos ... (1793-1803), pp. 73-75.

(37) RSEAPV. Actas V (1793-1803), p. 418. Junta de 29 de enero de 1800.

(38) Ibid. p. 578. Junta de 5 de agosto de 1801.

(39) RSEAPV. 1801. C-34, II. Industria, comercio y artes, n³.

(40) ibid.

(41) RSEAPV. Actas V (1793-1803), Junta de 25 de noviembre de 1801.

(42) RSEAPV. Libro Copiador de Oficios y Avisos ... (1793-1803), Oficio de 9 de febrero de 1803 .

(43) RSEAPV. 1836. C-91. V. Varios, $\mathrm{n}^{\circ} 2$.

(44) RSEAPV. Actas V (1793-1803), p. 15. Junta de 15 de enero de 1794.

(45) Ibid. p. 18. Junta de 29 de enero de 1794. 
(46) RSEAPV. 1794. C-24, I. Agricultura, n 5. "Informe sobre los Montes del Reino". Valencia 26 de abril de 1794.

(47) RSEAPV. Actas V (1793-1803), pp. 37-38.

(48) Ibid. pp. 504-505.

(49) RSEAPV. 1800. C-33, VI. Memorias, $n^{2} 3.1$. "Extracto crítico-analítico de una Memoria de Montes por el socio D. Joaqn. de La Croix".

(50) La citada Memoria aparece en Junta Pública de la Real Sociedad Económica de Amigos del país de Valencia celebrada el día 9 de diciembre de 1800. Benito Monfort, Valencia, 1801, pp. 163-267.

(51) RSEAPV. Actas V (1793-1803), p. 648. Junta de 3 de marzo de 1802.

(52) RSEAPV. Libro Copiador ... (1793-1803), pp. 203-205. Oficio de 3 de marzo de 1802.

(53) Novísima Recopilación de las Leyes de España, t. VI. Indices. Título XXIV, Suplemento de 1805 y 1806 . Madrid, 1807, p. 56.

(54) RSEAPV. 1807. C-47, I. Agricultura, n 11. "Prospecto de una obra de Montes y Bosques por D. Joaquín de Lacroix". El prospecto fue aprobado por Real Orden de 12 de abril de 1805, pese a que en la signatura del archivo de la Sociedad se coloca en 1807. Evidentemente se trata de un error de clasificación.

(55) Novisima Recopilación..., t. IV, Libro IX, Título XX, p. 395.

(56) Ibid., pp. 395-400.

(57) J. VERNET: op. cit., p. 189

(58) Diego de Torres: Memoria en que se demuestran las utilidades que resultarán de usar el carbón de piedra de las minas de Utrillas, y demás del Reyno, y modo de conducirlo con mayor economía y beneficio a esta capital y otras partes. La escribió debió por Comisión de la Real Sociedad Aragonesa D. ..., Individuo, y Secretario perpetuo de la misma. Imp. de Blas de Miedes, Zaragoza, 1785.

(59) RSEAPV. Actas III (1795-1780), s.f. Junta de 22 de septiembre de 1785.

(60) Ibid. Juntas de 30 de julio y 3 de septiembre de 1788.

(61) RSEAPV. Actas V (1793-1803), pp. 77-78.

(62) RSEAPV. 1795. C-25, II. Industria, comercio y artes, $\mathrm{n}^{\circ} 1$.

(63) RSEAPV. Actas V (1793-1803), p.760. Junta de 6 de diciembre de 1802.

(64) Memoria en que se da noticia de varias minas de carbón de piedra en el Reino de Valencia y que trata de su explotación, uso, preparaciones, gastos y análisis, premiada por la Real Sociedad Económica de Amigos del País de Valencia en su Junta Pública de 9 de diciembre de 1802 y escrita por D. Joaquín de La Croix y Vidal.Benito Monfort, Valencia, 1803. 108 págs. El manuscrito original se conserva en RSEAPV. 1802. C-39, VI Memorias, $\mathrm{n}^{\circ} 4.2$.

(65) Jose Francisco FORNIES CASALS: La Real Sociedad Económica Aragonesa de los Amigos del País en el periodo de la Ilustración (1776-1808): sus relaciones con el artesanado y la industria, Zaragoza, 1978, pp. 264, 266 y 303-305.

(66) J. VERNET. op. cit., p. 193.

(67) En Junta Pública de la Real Sociedad Económica de Amigos del País celebrada el día 9 de diciembre de 1804, Benito Monfort, Valencia, 1805, pp. 113-138.

(68) F. de P. PAVIA: Galería biográfica..., op. cit. p. 67. 
(69) Ibid.

(70) Junta Pública de la Real Sociedad Económica de Amigos del País de Valencia celebrada en día 10 de diciembre de 1806, Benito Monfort, Valencia, 1807, p. 65.

(71) F. de P. PAVIA: op. cit., p. 68. de 1801 .

(72) RSEAPV. Actas V (1793-1803), Juntas de 30 de mayo de 1800 y 1, 8, 15 y 22 de julio

(73) RSEAPV. Actas V (1793-1803), pp. 759-761, Junta de 1 de diciembre de 1802.

(74) RSEAPV. Libro Copiador ... (1793-1803), pp. 240-241. Oficio de 25 de junio de 1802.

(75) RSEAPV. Actas V (1793-1803), pp. 652-655.

(76) La delicada situación financiera de la Sociedad en los años iniciales del siglo XIX ha sido tratada en el cap. 10 del trabajo de F. ALEIXANDRE: "La lucha por un presupuesto estable", en La Real Sociedad..., op. cit., pp. 289-325.

(77) RSEAPV. 1836. C-91, V. Varios, n².

(78) Ibid.

(79) La Murciana cuenta con un trabajo extenso editado últimamente por Matías VELAZQUEZ MARTINEZ: La Sociedad Económica de Amigos del País del Reino de Murcia: la Institución, los Hombres y el Dinero (1777-1820), Murcia, 1989. En la pág. 162 señala: "Entre los amigos del País de Murcia residentes en Madrid a la altura de 1815 y, por lo tanto, teóricos colaboradores de la Diputación Permanente, se menciona a: Joaquín de Lacroix (...)".

(80) F. de P. PAVIA: op. cit., p. 68.

(81) Joaquín FERNANDEZ PEREZ: "La Ciencia Ilustrada y las Sociedades Económicas de Amigos del País" en M. SELLES et al (comp.): Carlos III y la Ciencia ..., op. cit., pp. 223-224.

Murcia: la Institución, los Hombres y el Dinero (1777-1820), Murcia, 1989. En la pág. 162 señala: "Entre los amigos del País de Murcia residentes en Madrid a la altura de $1815 \mathrm{y}$, por lo tanto, teóricos colaboradores de la Diputación Permanente, se menciona a: Joaquín de Lacroix (...)".

(80) F. de P. PAVIA: op. cit., p. 68.

(81) Joaquín FERNANDEZ PEREZ: "La Ciencia Ilustrada y las Sociedades Económicas de Amigos del País" en M. SELLES et al (comp.): Carlos III y la Ciencia ..., op. cit., pp. 223-224. 